\title{
Long-Lived Metallized Tips for Nanoliter Electrospray Mass Spectrometry
}

\author{
Gary A. Valaskovic and Fred W. McLafferty \\ Chemistry Department, Cornell University, Ithaca, New York, USA
}

\begin{abstract}
Sheathless electrospray at $\mathrm{nL} / \mathrm{min}$ flow rates combined with Fourier-transform mass spectrometry has made possible high resolving power $(>50,000)$ mass spectra of subattomole samples of $>8 \mathrm{kDa}$ proteins separated by capillary electrophoresis (Valaskovic, G. A.; Kelleher, N. L.; McLafferty, F. W. Science, 1996, 273, 1199-1202). However, for this new method the mechanical stability of the thin $(35$ to $100 \mathrm{~nm}$ ) gold film electrodes has limited tip lifetime to 15 to $30 \mathrm{~min}$. A technique for $\mathrm{SiO}_{x}$ coating of the gold is described that provides a steady ion current $( \pm 10 \mathrm{pA})$ for 1 to $2 \mathrm{~h}$, even with arcs or interruptions of the electrospray voltage. (c) 1996 American Society for Mass Spectrometry (f Am Soc Mass Spectrom 1996, 7, 1270-1272)
\end{abstract}

$\mathrm{E}$ lectrospray ionization (ESI) [1] has been a primary factor in the revolutionary new applications of mass spectrometry (MS) to large biomolecules, with special advantages of coupling to liquid chromatography [2] and capillary electrophoresis (CE) [3]. The development of a sheathless ESI emitter (1-3 $\mu \mathrm{m}$ orifice) of much lower flow rate (20-30 $\mathrm{nL} / \mathrm{min}$ ) [4] has also greatly lowered ESI sample requirements. A tapered tip modification combined with CE has recently made possible far lower flow rates $(<0.2 \mathrm{~nL} / \mathrm{min})[5,6]$, with measurement of ESI spectra from $0.9,0.7$, and 2.8 amol samples of $8.6,12$, and $29 \mathrm{kDa}$ proteins, respectively, at high resolving power $(\geq 50,000)[7]$ using Fourier-transform (FT) MS [8, 9].

Emitter durability is cited [5] as a major drawback for this attomol identification method. An evaporated gold coating at the tip (Figure 1) serves as an electrode for both ESI and CE; the poor adhesion of optimum thickness $\mathrm{Au}(\leq 100 \mathrm{~nm})$ films makes them highly susceptible to deterioration by electrical discharge and gives lifetimes of only 15 to $30 \mathrm{~min}$ with continuous ESI. Partial coating loss also requires adjustment of ESI voltages and tip position during spraying or after turning off, and then on, the ESI voltage. Micrometer scale peel back of the Au film from the top has been observed with light microscopy (Figure 1A). Kriger and co-workers [10] greatly enhanced the durability of the gold coating on a rounded ESI emitter of a $25 \mu \mathrm{m}$ inner diameter (i.d.) capillary by an extensive procedure for pretreatment of the fused silica with an organofunctional silane. However, for our emitters this treatment added a substantial risk of particle contamination and only provided a modest $10 \%-20 \%$ im-

Address reprint requests to F. W. McLafferty, Baker Chemistry Laboratory, Comell University, Ithaca, NY 14853-1301. provement in the Au coating lifetime [5], possibly because of the unusually small ( $\leq 5 \mu \mathrm{m}$ ) outer diameter (o.d.). Consistent with this, the Mann emitters [4] that last up to $3 \mathrm{~h}$ [11] have a 1-3 $\mu \mathrm{m}$ orifice in a metallized flat surface orthogonal to the capillary. Here we describe an overcoating of the $\mathrm{Au}$ film with $\mathrm{SiO}_{x}$ that greatly alleviates these problems.

\section{Experimental}

Standard emitter tips, fabricated from $20 \mu \mathrm{m}$ i.d. silica tubing as described previously [5-7], were vacuum sputter coated with Au to $\approx 100 \mathrm{~nm}$ thickness and overcoated by thermal evaporation with $\mathrm{SiO}$ to $\mathrm{a} \approx 10$ to $50 \mathrm{~nm}$ thickness (Figure 1B, C). Exposure of the $\mathrm{SiO}$ thin film to atmosphere rapidly forms a mixed $\mathrm{SiO} / \mathrm{SiO}_{2}\left(\mathrm{SiO}_{x}\right)$ insulating layer [12]. An emitter was mounted on an $X, Y, Z$ stage and electrical contact made with silver conductive paint $\approx 1 \mathrm{~cm}$ back from the tip.

\section{Results and Discussion}

For one of these emitters (Figure 1B, tip used), continuous ESI for $2 \mathrm{~h}$ of $10 \mu \mathrm{M}$ ubiquitin into a modified 6T Finnigan FTMS [8] gave the total ion current recording of Figure 2. This unusually constant current over $>10$ min periods $( \pm 50 \mathrm{pA}$ at the skimmer, $\pm 10 \mathrm{pA}$ at the ion cell) was achieved without any interim adjustments (including ESI voltage and emitter position). The slow overall rise in current has been observed previously and attributed to evaporative concentration of the sample [4]; the sample reservoir here also has some exposure to the atmosphere. Further, turning off and on the voltage that stops and starts ESI (current spikes marked by arrows, Figure 2) does not affect the 


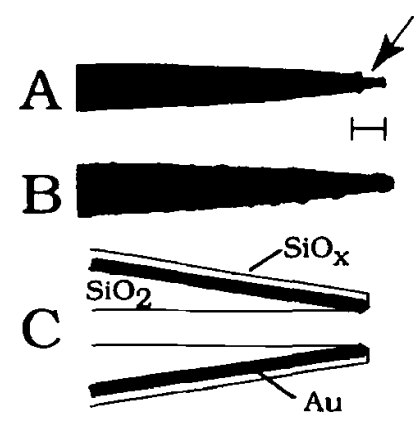

Figure 1. (A) Tip with uncoated Au electrode after $30 \mathrm{~min}$ ESI arrow, peeling coating (bar length $10 \mu \mathrm{m}$ ). (B) $\mathrm{SiO}_{x}$ over-coated tip after 2 h ESI. (C) Schematic (enlarged scale) of tip structure.

subsequent ion current level. In another experiment, high resolving power $\left(\approx 10^{5}\right)$ spectra having a high degree of similarity were measured after 40 and 60 min of spraying with no ESI adjustments (Figure 3). For all ten emitters tried with ubiquitin and equine myoglobin in this long-term experiment, ESI started easily and lasted more than $1 \mathrm{~h}$; later microscopic examination (Figure 1B) showed no loss of the gold coating, and tip clogging could be observed in most of the failed emitters. Rigorous attention to detail (e.g., centrifugal filtering of samples, emitter cleanliness) now limits tip clogging failure to once in several hours. Two emitters that suffered arcs still performed ESI effectively.

\section{Results}

$\mathrm{SiO}$ evaporation conditions must be carefully controlled to leave a ring of Au exposed at the end of the ESI tips (Figure 1C) for electrical contact. When the angle between the SiO evaporation (point) source and the capillary (emitter end) was decreased from $\approx 120^{\circ}$ to $90^{\circ}$ and the $\mathrm{SiO}_{x}$ thickness increased to $>50 \mathrm{~nm}$, the electrospray was more difficult to start, with mechanical abrasion [13] or arcs as effective initiators in some cases; apparently too little of the Au electrode was left exposed.

The Figure 3 spectra show adduct as well as $(M+$

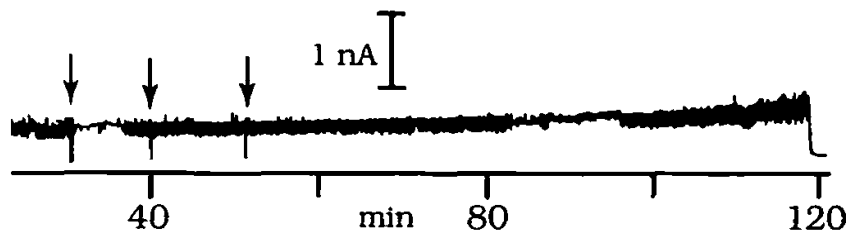

Figure 2. Total ion (skimmer) current for ESI ( $2 \mu \mathrm{L}$ of $10 \mu \mathrm{M}$ bovine ubiquitin, $2 \%$ HOAc, 17 $\mathrm{nL} / \mathrm{min}$ ) for $2 \mathrm{~h}$, until the sample was exhausted, with no adjustment of ESI conditions except off/on of ESI voltage at arrows.

A
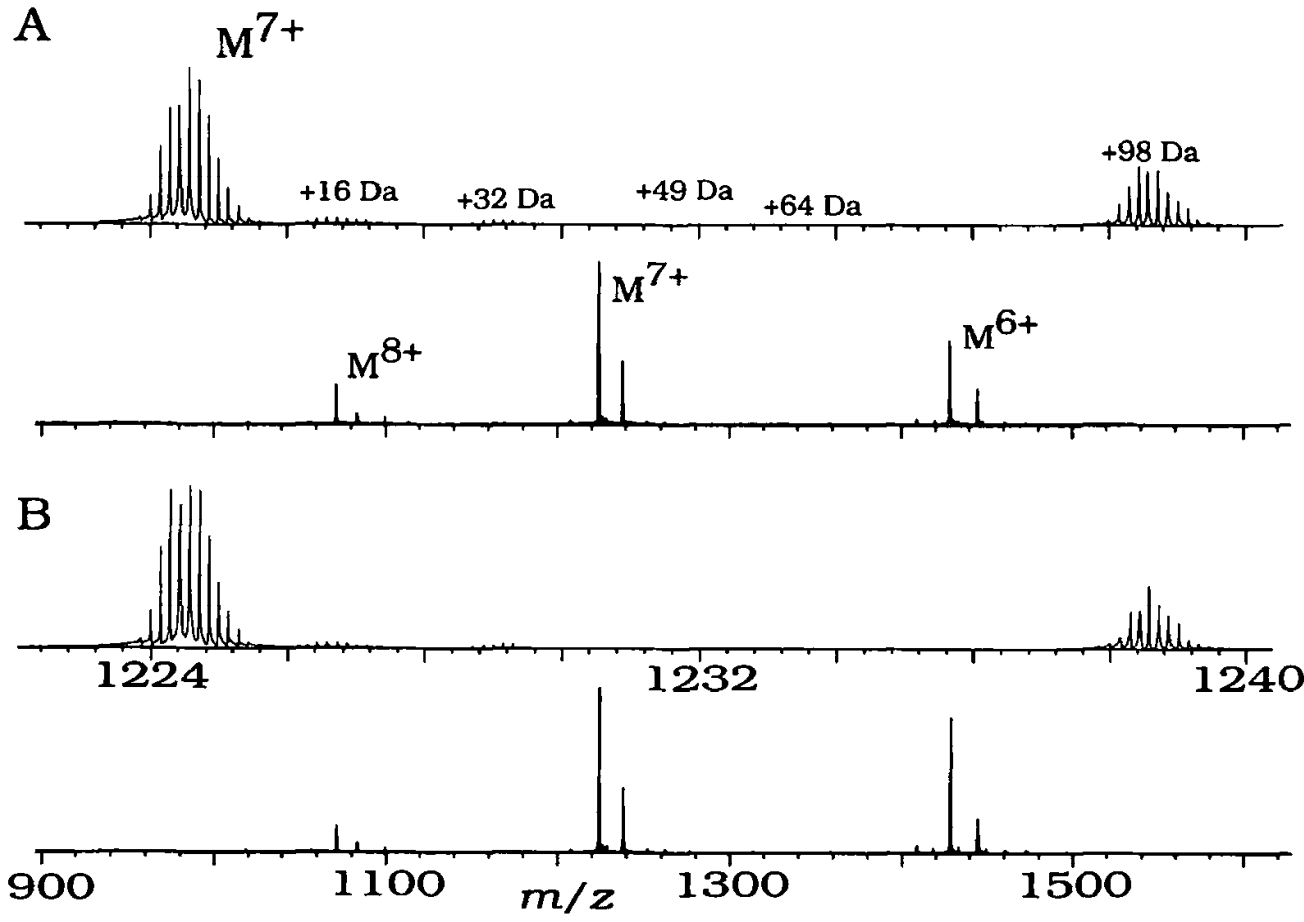

Figure 3. ESI spectra, same conditions as Figure 2, after (A) 40 and (B) $60 \mathrm{~min}$. Upper scales: expansion of lower scales. 
$n \mathrm{H})^{n+}$ peaks. Those of $(\mathrm{M}+n \mathrm{H}+98)^{n+}$ correspond to the addition of $\mathrm{H}_{3} \mathrm{PO}_{4}$ or $\mathrm{H}_{2} \mathrm{SO}_{4}$ [14]. However, the minor adducts at $+16(\mathrm{O}$ ?) [15], $+32(2 \mathrm{O}$ ?), +49 , and $+64(\mathrm{Cu}$ ?) $\pm 1 \mathrm{Da}$ have not been positively identified. Noting the possibility of electrochemical modification $[15,16]$, these minor adducts are under further investigation. These were not present in ESI spectra from similar experiments with another sample of ubiquitin or with myoglobin (10 $\mu \mathrm{M}$, aqueous), which contained only $5 \%-10 \%$ peaks representing apomyoglobin. A bovine hemoglobin spectrum showed a high proportion of homo- and mixed dimers of the $\alpha$ and $\beta$ proteins.

\section{Conclusions}

The $\mathrm{SiO}_{x}$ overcoating requires only a simple additional step to the $\mathrm{Au}$ vacuum coating process. This increases emitter lifetimes to 1 to $2 \mathrm{~h}$ and provides easy initiation and high stability of electrospray during this time, including stop-start capability and resistance to arcing destruction [17].

\section{Acknowledgments}

We appreciate the valuable advice and assistance of N. L. Kelleher, Z. Guan, E. K. Fridriksson, U. Haupts, the use of vacuum coating and tip preparation equipment of G. H. Morrison, and the financial support of the National Institutes of Health, Grant No. GM-16609.

\section{References}

1. Fenn, J. B.; Mann, M.; Wang, C. K.; Wong, S. F.; Whitehouse, C. M. Science 1989, 246, 64-71.

2. Banks, J. F.; Shen, S.; Whitehouse, C. M.; Fenn, J. B. Anal. Chem. 1994, 66, 406-414.

3. Smith, R. D.; Wahl, J. H.; Goodlett, D. R.; Hofstadler, S. A. Anal. Chem. 1993, 65, 574A-584A.

4. Wilm, M. S.; Mann, M. Int. I. Mass Spectrom. Ion Processes 1994, 136, 167-180.

5. Valaskovic, G. A.; Kelleher, N. L.; Little, D. P.; Aaserud, D. J.; McLafferty, F. W. Anal. Chem. 1995, 67, 3802-3805.

6. Valaskovic, G. A.; McLafferty, F. W. Rapid Commun. Mass Spectrom. 1996, 10, 825-828.

7. Valaskovic, G. A.; Kelleher, N. L.; McLafferty, F. W. Science 1996, 273, 1199-1202.

8. Beu, S. C.; Senko, M. W.; Quinn, J. P.; Wampler, F. M.; McLafferty, F. W. J. Am. Soc. Mass Spectrom. 1993, 4, 557-565.

9. McLafferty, F. W. Acc. Chem. Res. 1994, 27, 379-386.

10. Kriger, M. S.; Cook, K. D.; Ramsey, R. S. Anal. Chem. 1995. $67,385-389$.

11. Körner, R.; Wilm, M.; Morand, K.; Schubert, M.; Mann, M. J. Am. Soc. Mass Spectrom. 1996, 7, 150-156.

12. Holland, L. Vacuum Deposition of Thin Films; John Wiley: New York, 1956; pp 444-463.

13. Wilm, M. S.; Mann, M. Anal. Chem. 1995, 68, 1-8.

14. Chowdhury, S. K.; Katta, V.; Beavis, R. C.; Chait, B. T. J. Am. Soc. Mass Spectrom. 1990, 1, 382-388.

15. Morand, K.; Talbo, G.; Mann, M. Rapid Commun. Mass Spectrom. 1993, 7, 738-743.

16. VanBerkel, G. J.; Zhou, F. J. Am. Soc. Mass Spectrom. 1996, 7, 159-162.

17. Commercial production of these tips is being pursued by one of the authors (GAV). 